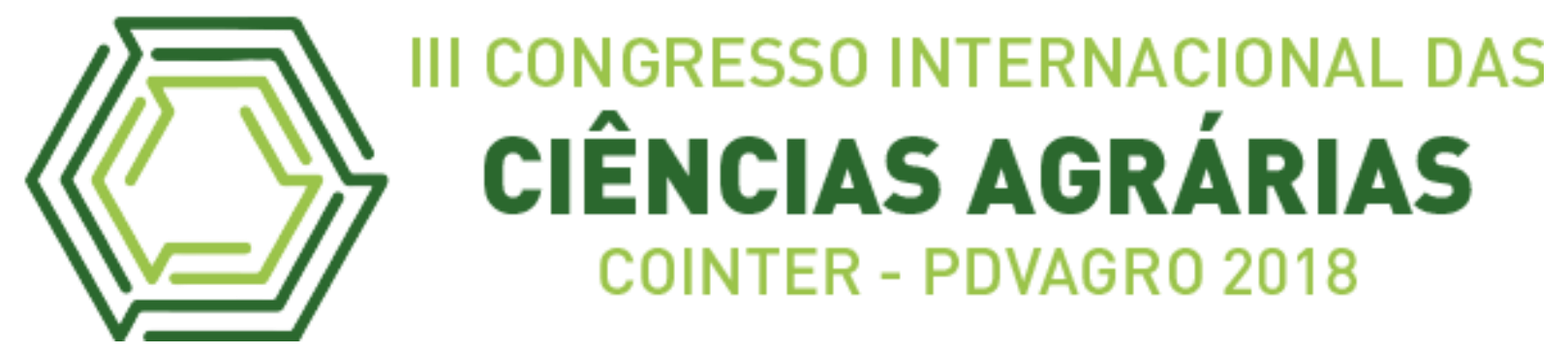

\title{
TESTE DE GERMINAÇÃO DE SEMENTES: SEMENTES DO QUIABO (Abelmoschus esculenta)
}

\section{SEED GERMINATION TEST: SEEDS OF QUIABO (Abelmoschus esculenta)}

Apresentação: Pôster

Marcelo Rodrigues Lima Filho ${ }^{1}$; Carlos Anderson Sousa de Carvalho ${ }^{2}$; Patrícia Taila Trindade de Oliveira ${ }^{3}$; Nalton Enderson Silva da Silva ${ }^{4}$; Félix Lélis da Silva ${ }^{5}$

DOI: https://doi.org/10.31692/2526-7701.IIICOINTERPDVAGRO.2018.00674

\section{Introdução}

A propagação de plantas a partir de sementes é reconhecida como um dos fatores fundamentais que afetam o recrutamento das plantas, é um importante passo do ciclo reprodutivo da maioria delas (DEMINICIS et al.,2009). As sementes desempenham um papel muito importante para o ser humano, decorrente, antes de tudo, do fato de que a evolução do gênero Homo se processou numa época geológica em que quase todos os tipos de vegetação terrestre do planeta já haviam sido dominados por plantas fanerógamas e a maior parte dos vegetais aproveitados pelo homem pertenciam a este grupo (LABOURIAU, 1990).

Para Deminicis et al., (2009) as sementes possuem uma alta capacidade de perpetuação e disseminação, e o grande sucesso dessas características é a capacidade de se distribuir no tempo e no espaço, a partir de seu mecanismos biológicos de propagação, devendo germinar quando as condições são adequadas para a manutenção do crescimento da plântula e subsequente desenvolvimento da planta.

Com o aumento da população mundial houve uma demanda muito grande por sementes geneticamente melhoradas com variedades que produzam mais em menor quantidade de tempo, com resistência a pragas e doenças. A produção de sementes de alta qualidade representa uma das principais prioridades para o sucesso da cultura, para testar o potencial fisiológico das sementes, deve-se fazer rotineiramente testes de germinações

\footnotetext{
${ }^{1}$ Curso de Agronomia, IFPA - Campus Castanhal/marcelolimalima@gmail.com;

${ }^{2}$ Curso de Agronomia, IFPA - Campus Castanhal/anderson_casc@hotmail.com;

${ }^{3}$ Curso de Agronomia, IFPA - Campus Castanhal/patriciatailaoliveira@gmail;

${ }^{4}$ Curso de Agronomia, IFPA - Campus Castanhal/naltonendersonsilva@gmail.com;

${ }^{5}$ Docente Doutor, IFPA - Campus Castanhal/felix.lelis@ifpa.edu.br
} 
baseados nas condições favoráveis como temperatura, umidade e substrato, permitindo a expressão máxima do potencial de germinação (LIMA et al.,2006), por conseguinte o teste de vigor de sementes tem sido de tamanha importância para o controle da qualidade das sementes, a qual este controle se estende até a comercialização, de forma a garantir a qualidade genética, fisiológica, sanitária e a pureza física (REIS, 2013).

As hortaliças, por serem espécies que possuem um ciclo curto, a velocidade de germinação das sementes também são pequeno, dessa forma, as sementes de olerícolas merecem uma atenção especial no que se refere à avaliação de sua qualidade fisiológica, Para isso, testes para determinação da germinação e do índice de velocidade de germinação (IVG) destas sementes devem ser utilizados com maior frequência (SILVA et al., 2011).

Para Lima et al., (2006) os teste de germinação em laboratório apresentam confiabilidade para analistas e produtores, porém deve-se considerar que estes testes, as sementes são submetidas a condições ideais para germinação não sendo eficiente para estimar o desempenho dos lotes avaliados em laboratórios em campo, a qual os resultados de emergência das plântulas podem não corresponder aos obtidos no teste de germinação, dessa forma, as empresas produtoras de sementes têm empregado métodos que permitam identificar diferenças no desempenho e vigor nos lotes com alta porcentagem de germinação, como ferramenta auxiliar em seus programas de controle de qualidade e nas decisões sobre os destinos dos lotes de sementes.

Torres et al., (2011) enfatiza que a utilização de sementes de alta qualidade constitui a base para o aumento da produtividade agrícola, o que é objeto de inúmeras pesquisas com outras espécies cultivadas, é ainda pouco pesquisado para algumas espécies olerícolas. Diante do exposto, o presente trabalho teve como objetivo avaliar a metodologia do teste de germinação e do vigor de sementes de Quiabo Santa Cruz 47 (Abelmoschus esculentus) em ambiente com temperatura e umidade controlada.

\section{Metodologia}

O teste de germinação das sementes de quiabo (Abelmochus esculentus) foi realizado no Laboratório Sementes do Instituto Federal do Para - Campus Castanhal, sob condições de ambiente controlado e favorável.

Para o teste de germinação com quiabo foi utilizado a metodologia do Ministério da Agricultura da Pecuária e Abastecimento (MAPA) exposta no Laboratório de análise de sementes LAS, (2009), onde foram utilizadas quatro placas de pétri, sendo estas condicionada 
por nove sementes cada. O substrato utilizado foram duas páginas de germitest umedecidas para o processo de germinação, este teste é caracterizado pela sigla $\mathrm{Sp}$, ou seja, teste sob papel. Em seguida estas foram conduzidas em germinadores de câmara vertical tipo B.O.D com temperatura de $25^{\circ} \mathrm{C}$, posteriormente umedecidas frequentemente. Após quatro dias foram feitas a primeira observação, e a segunda contagem foi a 21 dia após o processo de germinação.

\section{Resultados e Discussões}

A primeira análise das sementes quatro dias após início do experimento não apresentaram germinação completa (LAS, 2009), apenas com as radículas desenvolvidas, apresentando em torno de 33\% para todos os quatro tratamentos. Após 21 dias foi feito outra aferição na qual, os dados do experimento foram analisados e quantificados expressos na tabela 01 .

Tabela 01. Análise germinativa das sementes do quiabo (Abelmoschus esculentus) após 21 dias em estufa a temperatura controlada.

\begin{tabular}{|c|c|c|c|c|c|c|c|}
\hline \multirow{2}{*}{ Parâmetros } & \multirow{2}{*}{$\mathbf{N}^{\circ}$ GER } & \multicolumn{2}{|c|}{ NDC } & \multirow{2}{*}{ NDR } & \multirow{2}{*}{ PDPA } & \multicolumn{2}{|c|}{ DB } \\
\cline { 3 - 4 } \cline { 6 - 8 } Amostra & & $\mathbf{N}^{\circ}$ & $\boldsymbol{\%}$ & & & $\mathbf{N}^{\circ}$ & $\%$ \\
\hline $\mathbf{1}$ & 9 & 4 & 44,4 & - & - & 5 & 55,5 \\
\hline $\mathbf{2}$ & 9 & 2 & 22,2 & - & - & 7 & 77,7 \\
\hline $\mathbf{3}$ & 9 & 2 & 22,2 & - & - & 7 & 77,7 \\
\hline $\mathbf{4}$ & 9 & 3 & 33,3 & - & - & 6 & 66,6 \\
\hline
\end{tabular}

NDC - Não desenvolveram cotilédone; NDR - Não desenvolveram raízes; PDPA - Plântula deformadas por anomalia; GER - Germinações.

Observa-se na tabela acima, que todas as sementes colocadas em análises na câmara de germinação a temperatura de $25{ }^{\circ} \mathrm{C}$ após os 21 dias, obteve $100 \%$ aproveitamento germinativo, comprovando a veracidade da garantia do fabricante que assegurava $80 \%$ de germinação em campo, os resultados obtidos por Zanin et al. (1998), com a cultivar Amarelinho mostraram que os maiores valores para a porcentagem de germinação (acima de 92\%), foram obtidos de sementes oriundas de frutos colhidos aos 55 dias após a antese.

No entanto, ressalta-se que entre as mesmas, apresentou-se algumas anomalias germinativas como o não desenvolvimento completo dos cotilédones, entre 22,2 a 44,4\%. Sonnenberg (1985) explica que as sementes de quiabo apresentam dificuldades na germinação devido à presença de substâncias gordurosas na constituição de seu tegumento, que dificultam a absorção de água, fato que para Mayer e Poljakoff-Myber (1989) é explicado que mesmo submetidas às condições ótimas de umidade, luz, temperatura e oxigênio, essa espécie 
apresenta desuniformidade na germinação como consequência do estado de dormência das sementes.

Além disso, observou-se que algumas plântulas estavam com suas estruturas radiculares em estado de degradação, bastante sensível, que pode ter sido ocasionado pelo grau umidade no recipiente, resultado semelhante foi encontrado na pesquisa de Martins et al. (2011) que constatou que sementes oriundas de frutos dependendo do seu estado de maturação podem apresentar no teste final de germinação, deterioração das sementes.

\section{Conclusões}

As sementes do quiabo em condições favoráveis apresentam um rendimento satisfatório na germinação, comprovando a eficiência das sementes para esses ambientes, no entanto espera-se fazer também testes em campo para constar sua eficiência em meio sem o controle de biofísico.

\section{Referências}

DEMINICIS, B. B. et al. Dispersão natural de sementes: importância, classificação e sua dinâmica nas pastagens tropicais. Archivos de zootecnia, v. 58, p. 35-58, 2009.

LABOURIAU, Luiz Fernando Gouvêa. O interesse do estudo das sementes. Estudos avançados, v. 4, n. 9, p. 228-242, 1990.

LIMA, Tricia Costa; MEDINA, Priscila Frantin; FANAN, Sheila. Avaliação do vigor de sementes de trigo pelo teste de envelhecimento acelerado. Revista Brasileira de Sementes, v. 28, n. 1, p. 106-113, 2006.

MARTINS, C. A. da S.; LOPES, J. C.; MACÊDO, C. M. P. de. Tratamentos pré-germinativos em sementes de quiabo em diferentes estádios de maturação do fruto. Revista de Ciências Agrárias, v.32, n.1, p. 1759-1770, 2011.

MAYER, A. C.; POLJAKOFF-MAYBER, A. The germination of seeds. London: Pergamon Press, 1989. $270 \mathrm{p}$.

REIS, J. Analises De QualidaJde De Sementes De Soja. Relatório de Estágio de Graduação em Gestão de Agronegócio. Faculdade UnB Planaltina. 2013.

SILVA, C, E et al. Tratamentos pré-germinativos em sementes de quiabo em diferentes estádios de maturação do fruto. 2011.

SONNENBERG, P. Olericultura especial. Goiânia: UFG, 1985. 149 p.

TORRES, Salvador Barros et al. Diferenciação de lotes de sementes de quiabo pelo teste de envelhecimento acelerado. Ciência Rural, v. 44, n. 12, p. 2103-2110, 2014. 
ZANIN, A. C. W.; NAKAGAWA, J.; SETUBAL, J. W. Efeitos da idade dos frutos, método e condição de secagem sobre a qualidade de sementes de quiabeiro. Pesquisa Agropecuária Brasileira, v.33, n.7, p.1-5. 1998. 